\title{
The preliminary outcome of the combination of immunotherapy and targeted therapy after recurrence and metastasis for hereditary leiomyomatosis and renal cell cancer-a case report
}

\author{
Dechao Feng", Yubo Yang", Ping Han, Xin Wei \\ Department of Urology, Institute of Urology, West China Hospital, Sichuan University, Chengdu 610041, China \\ \#These authors contributed equally to this work. \\ Correspondence to: Xin Wei. Department of Urology, Institute of Urology, West China Hospital, Sichuan University, Guoxue Xiang \#37, Chengdu \\ 610041, China. Email: xweiwch@126.com.
}

\begin{abstract}
Hereditary leiomyomatosis and renal cell cancer (HLRCC)-associated kidney cancer is a rare and exceptionally aggressive, with early metastasis and die at a young age. Most reported patients usually present with back pain and hematuria, and died within 5 years after diagnosis. Currently, there is not a guideline or census about the management of HLRCC. On April 19, 2019, the Food and Drug Administration (FDA) of the USA approved the combination of pembrolizumab and axitinib for first-line treatment of patients with advanced renal cell carcinoma based on the results of KEYNOTE-426 trial. Thus, the combination of immunotherapy and targeted therapy should be considered for HLRCC. We present a case of 46-year-old man without family history, possessing specific mutation and sensitive to the combination of immunotherapy and targeted therapy. After he completed seven cycles of combined treatments, his discomfort improved and the lesions of pleura almost disappeared and the mass in the left kidney area was basically stable. This patient might be the first one to receive the combination therapy and the efficacy seemed acceptable.
\end{abstract}

Keywords: Hereditary leiomyomatosis and renal cell cancer (HLRCC); mutation; immunotherapy; targeted therapy; case report

Submitted Nov 05, 2019. Accepted for publication Dec 24, 2019.

doi: $10.21037 /$ tau.2019.12.37

View this article at: http://dx.doi.org/10.21037/tau.2019.12.37

\section{Introduction}

In 1973, the first case series of multiple cutaneous and uterine leiomyoma (MCUL) were described by Reed and his colleagues (1), and several aggressive renal cell cancers (RCCs) referred to as hereditary leiomyomatosis and RCC (HLRCC) were observed in some pedigrees thereafter (2). The most outstanding characteristic of HLRCC is the occurrence of multiple cutaneous leiomyomas (3) and most pedigrees with HLRCC include at least one person suffering from cutaneous manifestations (2). HLRCC is a hereditary cancer syndrome characterized by inactivation of the Kreb's cycle enzyme fumarate hydratase $(\mathrm{FH})$, and the variable development of uterine fibroids, cutaneous leiomyomas and renal cancer of type 2 papillary morphology which is usually refractory to current chemotherapy, radiotherapy and immunotherapy (4). However, RCC in HLRCC denotes a series of cystic, tubulo-papillary tumors linked together by cytological similarity (2). HLRCC-related renal cancers occurred in a subset of the HLRCC families, and the patients usually metastasize very early and die young. Herein, we present a case without family history, possessing a specific mutation. Most importantly, he was sensitive to the combination of immunotherapy and targeted therapy, which is the first reported case and may indicate a new direction for the management of HLRCC. We present the following case in accordance with the CARE Guideline (5).

\section{Case presentation}

A 46-year-old male complaining of an intermittent 
left-sided lumbago for 6 months and a weight loss of 4 kilogram $(\mathrm{kg})$ came to our center. He had received a laparoscopic left renal cyst decompression one year before, but the pathology report was unknown. No significant abnormalities were detected on abdominal and skin examination. He had no obvious family history. Specially, his dizygotic twin brother had no special history, neither did his parents and son.

Left radical nephrectomy and colon repair were conducted secondary to percutaneous embolization of left renal artery. The pathology reported as follow: FH (negative expression on tumor cell, but positive on control), PAX2(+), PAX8(+), SDHB(+), Inil(+), EMA(+), Ksp-cad(+), AMACR(-), CD10(-), TFE-3(-), RCC(-), CK7(-), CD117(-), Ki-67(+, 5-15\%). These results indicated that it was likely to be HLRCC. His genetic assay (Figure 1) reported that a missense mutation (c.1256C > T) was detected in the FH gene, which resulted in the mutation (p.Ser419Leu) of the amino acid at position 419 of the $\mathrm{FH}$ gene-encoded protein from serine to leucine. Protein function was predicted by sorting intolerant from tolerant (SIFT) and Mutation taster and the results were shown to be harmful. This mutation was an unidentified mutation. The patient was regularly checked for chest and abdomen computerized tomography (CT) every 3 months after surgery.

At 16 months after surgery, the patient suffered from right-sided considerable pleural effusion and related symptoms, including cough, dyspnea, chest pain, and hyperpyrexia. CT of chest and abdomen indicated local recurrence and pleural metastasis. Then, a thoracoscopic biopsy was operated and confirmed the metastasis of pleura by pathology. On the one hand, a thoracentesis drainage was performed to release his discomfort. On the other hand, the combination of programmed cell death protein 1 (PD-1) immunotherapy (sintilimab $200 \mathrm{mg}$ ivgtt $\mathrm{q} 3 \mathrm{w}$ ) and vascular endothelial growth factor receptor (VEGFR) inhibitor (Axitinib, $5 \mathrm{mg}$ po bid) was given to him simultaneously. One month later, the lesions of pleura and left kidney area significantly reduced. Pleural effusion also subsided.

To date the patient has completed 7 cycles of immunotherapy with targeted therapy. Additionally, he did not complain any discomfort since the combination. The lesions of pleura almost disappeared and the mass in the left kidney area was basically stable. The CT images throughout the period were presented in Figure 1 and the timeline picture were shown in Figure 2.

\section{Discussion}

HLRCC, also known as MCUL, is an autosomal dominant tumor predisposition syndrome characterized by heterozygous germline mutations in the $\mathrm{FH}$ gene, which encodes the FH enzyme and subsequently catalyzing the conversion of fumarate to malate in the Kreb cycle $(3,6)$. To date, at least 71 malignant kidney tumors have been identified in the HLRCC families (3). However, the mutation in the present study has been firstly reported by our institution. Of note, the patient in this paper is the only person who has HLRCC in his family, and he has no medical history of cutaneous and abdominal leiomyomatosis. We presume that this may be associated with his unique type of mutation. As an aggressive renal malignance, HLRCC might have metastasized at the time of diagnosis. Most reported patients died within 5 years after diagnosis (3). Additionally, a cystic neoplasm was deemed to be premalignant due to activation of the hypoxia pathway for HLRCC (7), which was in accordance with the present case.

Although there has not been a guideline or census on the management of HLRCC yet, radical nephrectomy is recommended as the optimal intervention for certain patients. More novel methods of therapy, especially targeted therapy and immunotherapy, might be inspiring to improve the prognosis of advanced RCC, which would also throw new light upon HLRCC. On April 19th, 2019, the FDA of the USA approved the combination of Pembrolizumab and Axitinib for first-line treatment of patients with advanced RCC based on the results of KEYNOTE-426 trial (8). In the meantime, another trial (9) showed that Avelumab plus Axitinib resulted a longer progression-free survival than Sunitinib alone for advanced RCC. Thus, the combination of immunotherapy and targeted therapy was applied for the present patient after progressive disease (PD). To our acknowledgement, he is the first one reported to receive the combination therapy. After completing seven cycles of combined treatments, he did not complain any discomfort improved. The lesions of pleura almost disappeared and the mass in the left kidney area was assessed as stable disease (SD). Additionally, the patient also thinks that this treatment has been effective due to improved symptoms and wellcontrolled metastasis. Considering that HLRCC is a progressive renal malignance and has high risk of recurrence and metastasis, adjuvant therapy (targeted therapy, immunotherapy or combination of both) would 
A
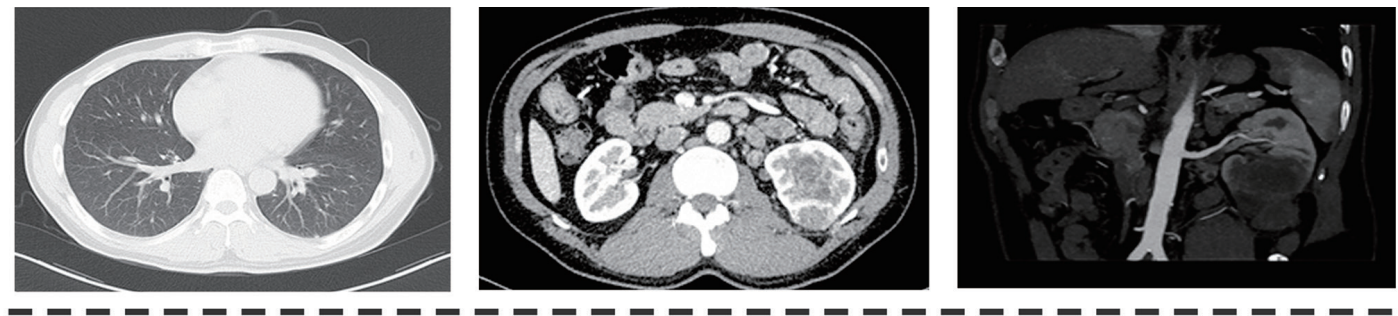

-

B

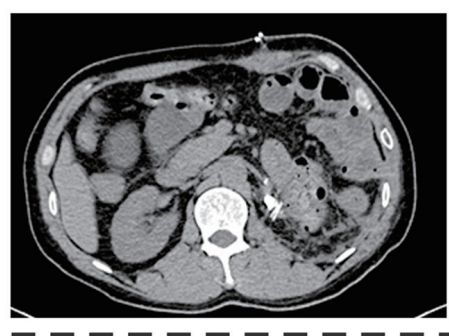

- - - - - - - - - - - -

C
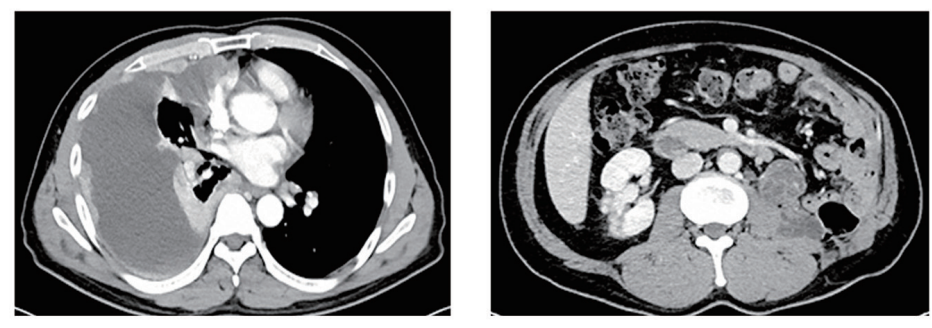

-ーーーーーーーーーーーーー

D
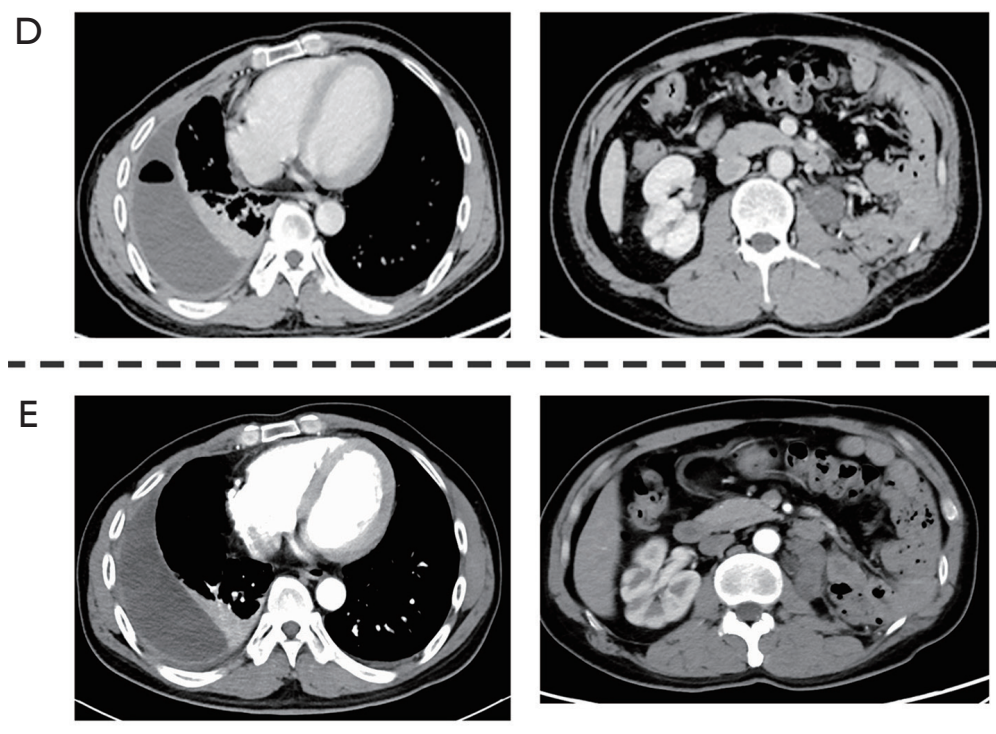

\begin{tabular}{c|c|c|c|c|c|c|c|}
\hline & Gene & Amino acid change & Gene subregion & Heterozygous & Functional change & Genetic mode & Mutation type \\
\hline FH & p.Ser419Leu & CDS9 & $\begin{array}{c}\text { Heterozygous } \\
\text { mutation }\end{array}$ & Missense & $\begin{array}{c}\text { Autosomal dominant } \\
\text { inheritance }\end{array}$ & $\begin{array}{c}\text { Unknown } \\
\text { mutation }\end{array}$ \\
\hline
\end{tabular}

Figure 1 The CT images throughout the period: (A) before surgery: the CT showed no metastasis of chest but indicated the invasion to colon; (B) at 10 days after surgery; (C) when local recurrence and pleural metastasis occurred; (D) at 47 days after immunotherapy and targeted therapy: the mass in the left kidney area, right pleural effusion and nodules reduced; (E) at 145 days after immunotherapy and targeted therapy: right pleural effusion reduced and the nodules almost disappeared; the mass in the left kidney area was basically stable; (F) genetic assay report. 


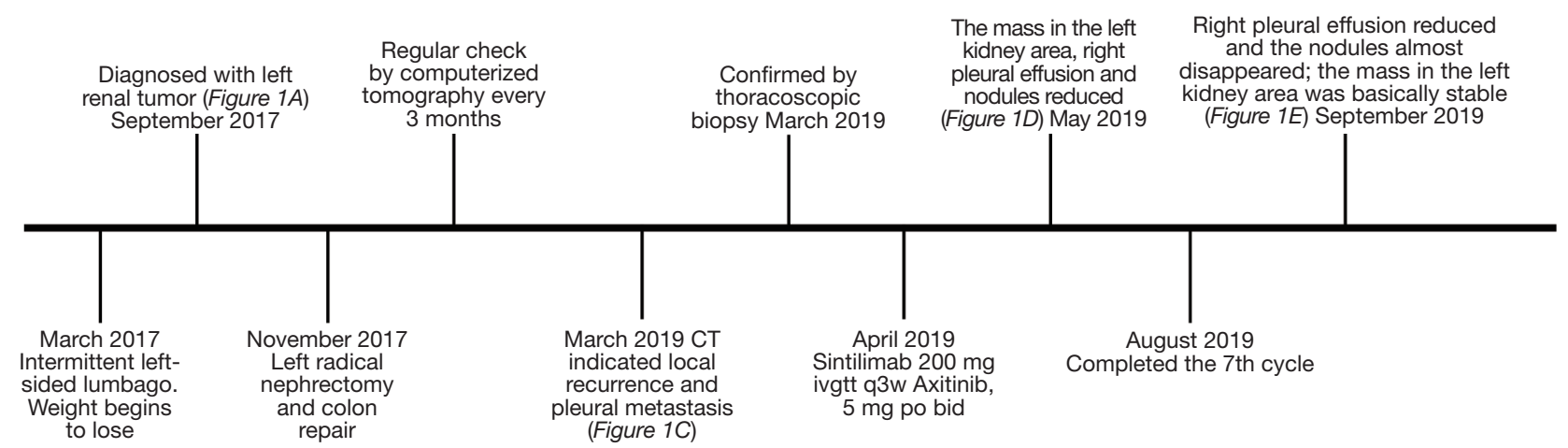

Figure 2 The timeline picture of this case.

be better to performed as soon as possible after surgery, rather than till to progression. Although many questions remain to be answered, for example, how to predict the reaction to adjuvant therapy is unclear. We do have the following limitations. As HLRCC is an extremely rare cancer and clinical trials with a large sample size are difficult to conduct, we only reported a single case, providing limited evidence for the management of HLRCC. Moreover, the long-term survival results are not available currently. Further cases of targeted therapy and immunotherapy in HLRCC should be carefully concluded to help to determine the role of these two treatments in HLRCC.

\section{Conclusions}

In summary, it may be promising for patients with HLRCC receiving immunotherapy and targeted therapy after surgery. But many questions are required to response, such as the time of beginning therapy, and the efficacy of different types of management.

\section{Acknowledgments}

Funding: The study was supported by the 1.3 .5 project for disiplines of excellence, West China Hospital, Sichuan University (ZY2016104) and Pillar Program from Department of Science and Technology of Sichuan Province (2018SZ0219).

\section{Footnote}

Conflicts of Interest: All authors have completed the ICMJE uniform disclosure form (available at http://dx.doi. org/10.21037/tau.2019.12.37). The authors have no conflicts of interest to declare.

Ethical Statement: The authors are accountable for all aspects of the work in ensuring that questions related to the accuracy or integrity of any part of the work are appropriately investigated and resolved. Informed consent was obtained from the patient included in this study.

Open Access Statement: This is an Open Access article distributed in accordance with the Creative Commons Attribution-NonCommercial-NoDerivs 4.0 International License (CC BY-NC-ND 4.0), which permits the noncommercial replication and distribution of the article with the strict proviso that no changes or edits are made and the original work is properly cited (including links to both the formal publication through the relevant DOI and the license). See: https://creativecommons.org/licenses/by-nc$\mathrm{nd} / 4.0 /$.

\section{References}

1. Reed WB, Walker R, Horowitz R. Cutaneous leiomyomata with uterine leiomyomata. Acta Derm Venereol 1973;53:409-16.

2. Refae MA, Wong N, Patenaude F, et al. Hereditary leiomyomatosis and renal cell cancer: an unusual and aggressive form of hereditary renal carcinoma. Nat Clin Pract Oncol 2007;4:256-61.

3. Lehtonen HJ. Hereditary leiomyomatosis and renal cell cancer: update on clinical and molecular characteristics. Fam Cancer 2011;10:397-411.

4. Kerins MJ, Milligan J, Wohlschlegel JA, et al. Fumarate 
hydratase inactivation in hereditary leiomyomatosis and renal cell cancer is synthetic lethal with ferroptosis induction. Cancer Sci 2018;109:2757-66.

5. Riley DS, Barber MS, Kienle GS, et al. CARE guidelines for case reports: explanation and elaboration document. J Clin Epidemiol 2017;89:218-35.

6. Venables ZC, Ramaiya A, Holden S, et al. Hereditary leiomyomatosis associated with renal cell carcinoma. Clin Exp Dermatol 2015;40:99-100.

7. Pollard PJ, Spencer-Dene B, Shukla D, et al. Targeted

Cite this article as: Feng D, Yang Y, Han P, Wei X. The preliminary outcome of the combination of immunotherapy and targeted therapy after recurrence and metastasis for hereditary leiomyomatosis and renal cell cancer-a case report. Transl Androl Urol 2020;9(2):789-793. doi: 10.21037/tau.2019.12.37 inactivation of fh 1 causes proliferative renal cyst development and activation of the hypoxia pathway. Cancer Cell 2007;11:311-9.

8. Rini BI, Plimack ER, Stus V, et al. Pembrolizumab plus Axitinib versus Sunitinib for Advanced Renal-Cell Carcinoma. N Engl J Med 2019;380:1116-27.

9. Motzer RJ, Penkov K, Haanen J, et al. Avelumab plus Axitinib versus Sunitinib for Advanced Renal-Cell Carcinoma. N Engl J Med 2019;380:1103-15. 